\title{
Hairdressing in space: Depiction of gender in science books for children
}

\author{
E. F. Caldwell* \\ School of Art, Design and Architecture, University of Huddersfield, Huddersfield, HD1 3DH, UK \\ e-mail: e.caldwell@hud.ac.uk \\ S. Wilbraham \\ Health, Psychology and Social Studies, University of Cumbria, Fusehill Campus, Carlisle, CA1 2HH, UK \\ e-mail: susan.wilbraham@cumbria.ac.uk
}

\begin{abstract}
Stereotypes in the media both reflect and perpetuate the notion that science is a masculine pursuit. The aim of the current study is to explore whether such stereotypes extend to imagery within children's science books. In order to determine the extent of stereotypes in gender representation both quantitative and qualitative analyses were conducted. Results demonstrated that overall females were under-represented in images across the books surveyed. Analyses of images of adults demonstrated under-representation of women in both physics and mathematics books, but images of children showed no significant difference between genders. Analyses of the target age of the children's books revealed that books targeted at older children contained fewer images of adult females. Qualitative visual analyses revealed that books about space exploration trivialized women's expertise, diminished their perceived technical competence, failed to acknowledge their contribution or presence, and represented them in a manner which suggested that they were passive, lower status, and superficial. Books about science that are currently available to children in libraries are not balanced in terms of their representation of gender. Imagery in children's books of women actively participating in scientific occupations would help to demonstrate that careers in these areas are meaningful, fulfilling and achievable for women.
\end{abstract}

Keywords Gender-STEMM stereotypes; women in STEMM; unconscious bias; children's science trade books; visual analysis

\section{Introduction}

Despite intense scrutiny and research in a variety of fields and disciplines, the gender gap in science engagement continues to be an enduring social problem with women underperforming in science education and being under recruited in the scientific workplace (O'Brien et al. 2015). While overall representation of women in Science, Technology, Engineering, Mathematics and Medicine (STEMM) is low, this is not the case for all scientific fields (Yang \& Barth 2015). Statistics for gender representation in employment reveal that women are equally represented in biological and medical fields but underrepresented in physics, engineering and maths. For example, 45 per cent of registered doctors in the UK are female with more women than men currently training to be doctors (General Medical Council 2016). In contrast, only 6 per cent of registered engineers in the UK are women, and only 20 per cent of 
students taking Physics A-level are female, a statistic that has not changed in 25 years (Women's Engineering Society 2016).

It has been suggested that factors outside of school are influential in boys developing a preference for physics, rather than biology, and that to understand socialization processes, it is necessary to investigate the influences on young children (Baram-Tsabari and Yarden 2008). Books, along with other media, provide children with a way to learn about people and places far beyond their realm of day-to-day experience, and are 'a macrocosmic resource through which they can discover worlds beyond their own life-space' (Peterson \& Lach 1990: 189 cited in Gooden \& Gooden 2001: 91). This is particularly relevant to learning about science as few children have ever been inside a laboratory, or met an astronaut. In fact, Flicker (2003) claims that 'most people have never, and will never, personally meet a scientist' ( $p$. 307). Despite the disparity between science disciplines in terms of gender representation, few studies have explored the differences between the STEMM fields that are gender balanced or female dominated, such as health, and those that are male dominated, such as engineering. The aim of the current study is to examine gender representation in different disciplines in one important early source of information about science, namely children's science books.

\section{Literature Review}

\section{Stereotypes, gender and STEMM}

Research exploring implicit associations between STEMM and gender reveals that that 72 per cent of more than 2.5 million Americans, consider science to be masculine and humanities to be feminine (Nosek et al. 2007). Cheryan et al. (2016) found that science disciplines that are perceived as having a more masculine culture are less attractive to women and deter them from studying these subjects. As Harding (1986: 63) points out, 'scientific' and 'masculine' are mutually reinforcing cultural constructs' and goes on to explain:

The effects of gender stereotyping, which begin in the cradle, accumulate through childhood, adolescence, and adulthood in such a way as to systematically discourage women and encourage men to engage in the kinds of thinking and motor activity necessary for skill in scientific, mathematical, and engineering work.

Gender-STEMM stereotypes have been found to develop as early as the age of eight (Cvencek, Meltzoff \& Greenwald 2011) and by the age of nine, gender-STEMM stereotypes have been found to predict achievement in maths for girls but not boys (Steffens, Jelenec \& Noack 2010). By middle school, math=male stereotypes have started to influence girls' performance and sense of belonging in maths and their confidence and liking for the subject begins to wane (Good, Aronson \& Harder 2008). Nosek et al. (2009) studied data from 34 countries and found that countries with greater levels of gender-STEMM stereotyping, had a greater difference in performance between boys and girls in 8th grade science and maths exams.

In an era of political correctness, gender-science stereotypes are rarely explicitly endorsed (Nosek et al 2009: 10594). However, unconscious bias can affect both teachers and students' attitudes to girls being 
interested in, and performing well in science. Beilock et al. (2010) found that anxieties of female elementary school teachers about maths can affect girls', but not boys', maths achievement. In addition, Makarova and Herzog (2014) found that senior students in secondary schools, and their science teachers, negatively associate girls with maths. According to Kiefer \& Sekaquaptewa (2007) reminding female university students of the maths=male association can damage their performance in maths examinations, although if the stereotype is removed, women outperform men (Good et al. 2008).

Gender-STEMM stereotypes are both reflected and reinforced by mainstream media in terms of failing to acknowledge the contribution of women, or diminishing their technical expertise. There are a number of studies which explore representations of female scientists in adult media, such as newspapers (Shachar 2000), journal advertising (Barbercheck 2001), magazines (LaFollette 1988), and film (Flicker 2003; Steinke 2005). These studies all found evidence of gender stereotyping, including much lower levels of representation of women in science (Barbercheck 2001; Sachar 2000). Where female scientists do appear studies have found a more subtle form of stereotyping occurring, such as emphasizing their physical appearance and romantic lives (Flicker 2003; Steike 2005). O'Keffe (2013: 12) interviewed STEMM professionals about the influence their media consumption had on their career choices and a number of female respondents described 'actively looking for representations of women in the sciences and not finding adequate role models'. Of the small amount of work that has distinguished between STEMM fields, there is some indication of a historical association of women with some science subjects, but not others. In LaFollette's (1988: 264) study of magazine articles about science from 1910-1955:

No woman, either scientists or journalist, was listed as the author of an article on mathematics, astronomy, archaeology or palaeontology, despite the fact that women were actively engaged in research in those fields. Women authors tended to write about research in the social or biological sciences [...] but were much less visible as authors of articles on physics or chemistry.

There have also been studies of the representation of scientists in children's media. Long et al.(2010) studied portrayals of scientists in television programmes popular among twelve to fourteen year olds and found that male scientists significantly outnumbered female scientists, although gender stereotyped behaviour was absent in the scientist characters. In contrast, science education television programmes show some evidence of gender counter-stereotyping with males and females equally likely to be scientists (Long, Boiarsky \& Thayer 2001).

\section{Gender-STEMM stereotypes and children's books}

There have been numerous studies of gender representation in children's non-science literature, which have all shown an imbalance in the representation of males and females, with some studies finding nearly twice as many male main characters as female (Hamilton et al. 2006). The well-established dearth of females in children's books is argued to represent a 'symbolic annihilation' as underrepresentation denies the existence of women and girls (McCabe et al. 2011: 198). In addition to the imbalance in the number of males and females that feature in children's books, other forms of sexism also exist in children's literature, including segregated domestic and professional roles, unequal portayals of status 
between genders, personality stereotypes and an 'idealization of femininity' (Diekman and Murnen 2004: 373). The research on children's literature overwhelmingly suggests that children's books communicate the message: 'It's a man's world, kids!' (Bender \& Leone 1989: 36 cited in Gooden \& Gooden 2001: 92).

Gender stereotypes in children's books increase in intensity as the target age of the books rises (Evans \& Davies 2000). This trend also applies to characters within books and a number of studies have found that the representation of girls and boys is more equitable than that of adults (Gooden \& Gooden 2001; Hamilton et al. 2006; McCabe et al. 2011). It has been argued that this 'implies that girls do not grow up and become forces in their world, but rather remain young and vulnerable' (Fitzpatrick \& McPherson 2010: 136). Examinations of illustrations reveal that girls' roles are portrayed as more flexible than those of adult women (Fitzpatrick \& McPherson 2010; Jackson \& Gee 2005). As Jackson and Gee (2005: 124) describe: 'it seems that "girls can do anything" but when girls become women/mothers their "doing" is restricted to housework and childcare'.

\section{The visual language of sexism}

Images play an important role in demonstrating and validating the messages within text, and they should be considered both influential and worthy of scrutiny. According to Ali (2012: 284), visual images can be regarded as 'texts' and can be analysed or 'read' as cultural artefacts. Emmison and Smith (2000: 66) point out that images in the public domain, such as in the media and advertising both indicate the shared ideologies and beliefs of a culture but also help to shape them. Barbercheck (2001) studied advertisements in the prestigious journal Science, and found that female models pictured using scientific equipment are often paired with the message that the machine is easy or simple to use. In contrast, when male models are used, the accompanying text emphasizes words such as 'fast, accurate or reliable' (Barbercheck 2001: 126). Barbercheck (2001: 131) comments that the visual language used in adverts reflects the fact that "we live in a culture in which both men and women "know" that science is masculine'.

According to Gooden and Gooden (2001: 91), the stereotypes in children's book illustrations 'significantly affect gender development' and provide children with 'a stockpile of images for 'children's mental museums.' (Spitz 1999 cited Frawley 2008: 291). Jackson and Gee (2005: 117) point out that images can extend the meaning of text or can even tell a different story to the written text. A small number of studies of children's literature have focused on illustrations, and all found biased or stereotypical visual representations of gender. For example, female characters in children's' books are also often shown in lower status jobs such as secretaries rather than bosses (Diekman \& Murnen 2004), and males are more often pictured as adults or superheroes (Fitzpatrick \& McPherson 2010). Jackson and Gee (2005) found that girls and women were more likely to be pictured in sitting positions that appeared more submissive than the male characters and were literally taking up less space than men.

Gender roles are fostered within children's books illustrations in a manner which undermines efforts to represent women as competent with tools and equipment. In Poarch and Turner's (2001) study of children's book illustrations, women were more likely to be pictured with objects related to caring or 
domestic chores. Jackson (2007) found that children interpret the person pictured holding or using tools as the one able to do the job. In one of the books analysed by Jackson (2007), a female garage worker was pictured answering the phone and so was interpreted by the children as being the receptionist, whereas the male garage worker was shown fixing the car and was taken to be the mechanic. So, despite the fact that the book's producers had included a female garage worker, presumably in an effort at gender balance, children did not consider that the female worker has the skills or knowledge to fix cars as they were not the one shown with the relevant tools (Jackson 2007).

\section{Children's science books in public libraries}

Library books are an important source of information about science for the general public, because they are both free to use and accessible to everyone. Aside from the textbooks used in schools, the books that young children read to find out about science are science trade books, which often take the form of large format picture books. Trade books are aimed th the general public and form a major part of public and school library reference collections (Rawson \& McCool 2014). Barlow (1991: 166 cited in Rawson \& McCool 2014: 12) argues that 'children's trade books today are often a child's first introduction to science'. The few studies of children's science trade books carried out to date have found that depiction of scientists within children's science trade books are often inaccurate or derogatory, and the contributions of female scientists to public knowledge are essentially ignored (McArthur 1998; Rawson \& McCool 2014). McArthur (1998) found that popular histories of science and children's encyclopaedias 'focus almost entirely on men's contribution to scientific knowledge' (McArthur, 1998: 250).

Previous studies of images within children's trade books have focused on general science books, and have not examined differences in the representation of men versus women between the large range of subjects and professions found in STEMM. The aim of the current study of children's science books was therefore to examine whether differences exist in the portrayal of gender between books on different STEMM fields. The study was conducted in two parts. For the first part of the study, the following hypotheses were made based on past research: (1) That within STEMM books there would be a significantly greater number of males depicted than females. (2) That within STEMM books about gender balanced fields there would be no significant difference in the number of adult males than adult females depicted. (3) That within STEMM books for male dominated subjects there would be a significantly greater number of adult males than adult females depicted. (4) That within STEMM books there would be no significant difference in the number of female children compared to male children depicted. (5) That within STEMM books there would be a difference in the portrayal of gender in books aimed at young children and books aimed at older children, with gender-STEMM stereotypes increasing with the target age of the book. The second part of the study was an exploratory qualitative visual analysis, which aimed to examine the visual language of gender in STEMM books for children.

\section{Method}

\section{Design}

This study was conducted using a mixed method approach (Johnson, Onwuegbuzie, \& Turner 2007). Firstly, content analysis was performed on a large sample of illustrated children's science books, 
published between 1993 and 2015. Although this technique has been criticized for being largely a descriptive exercise, it does provide a means of ascertaining the "kind of world to which viewers are exposed' (Ali, 2012: 290). Content analysis aims to provide an objective view of a sample of media items, but in order to do this it relies on fixed, dichotomous categories that do not allow for an examination of the contextual meanings of gender (Jackson \& Gee 2005).

Following the content analysis, qualitative visual analysis was performed on of a sample of books that was small enough to enable close reading (Osei-Kofi \& Torres 2015). This analysis was conducted from the position of a critical approach to discourse, which assumes that both textual and visual discourse articulate and embed power relations and important social and cultural practices (Rose 2012). In a similar manner to Osei-Kfi \& Torres (2015), the current study used feminist theories of science to consider how gendered relations of power shape how STEMM is represented, and how women in STEMM are portrayed (Barbercheck 2001; Harding 1986). The aim of the qualitative part of the current study was to compare how women are portrayed in two different STEMM professions with different degrees of gender balance: Astronauts and Doctors. Both doctors and astronauts lend themselves to visual analysis as they have relatively clearly defined job roles, and have specific clothes, contexts and equipment that help to visually signify their role. In contrast to images of scientists, both doctors and astronauts commonly feature in literature for even very young children, and both doctors and astronauts are frequently chosen by children as the job that they would like to do when they grow up (Adams, 2015).

Sample

The books examined in this study were sampled from two public town libraries in different regions of the North of England. Library $A$ is an average sized town library, serving a population of approximately 100,000 people. Library B serves a population approximately four times larger than library A and is one of the largest town libraries in the UK. Whilst many previous studies of children's books have used prize winning books or databases of books in print, public libraries represent a more realistic sample of the books that are available to children (Hamilton et al. 2006; McArthur 1998; Poarch \& Monk Turner 2001). We acknowledge that there are also many online resources for children, however, analysing digital resources was outside the scope of this study.

Books for study were sampled from the 'Reference' or 'Information' sections of the junior book collection, which is aimed at children, aged between five and thirteen. Just as McArthur (1998) found, some topics and subject areas are well represented in children's libraries, whereas other STEMM subjects have surprisingly little presence. Subject areas were chosen if they related to STEMM topics on the curriculum at secondary and tertiary level, and if there were sufficient books in stock on shelves for analysis. The subjects and topics chosen for analysis were: Maths, Physics (space \& astronomy) and Biology (human biology \& medicine). There were not enough books available on the shelves about chemistry for analysis, and a search of the library catalogues showed that books about chemistry were stocked much less frequently than books about maths, physics or biology. All large format picture reference books in the selected subject areas were included in the sample, unless they contained no images of humans where gender could be assigned (eight books) or were duplicates. The total sample 
comprised of 160 books (see Table 1) and bibliographic data on each book in the final sample was collected from the library catalogues and online searches.

Table 1: Total number of books analysed by library and subject

\begin{tabular}{|l|l|l|l|}
\hline & Library A & Library B & Total \\
\hline Biology & 14 & 63 & 77 \\
\hline Maths & 9 & 21 & 30 \\
\hline Physics & 11 & 42 & 53 \\
\hline Total & 34 & 126 & 160 \\
\hline
\end{tabular}

From the total sample of 160 children's science trade books, books were included in the qualitative study if they contained photographs of astronauts or doctors where gender was clearly identifiable. In total, eighteen books featuring astronauts and eight books about doctors were included in the qualitative study.

\section{Quantitative procedure: Content analysis}

Each book was taken in turn and all the people pictured in the books, both in photographs and illustrations, were coded, including those on the front and back cover. The categories used for coding were: man, woman, boy, girl or unclassified if the gender or age were not clearly identifiable, for example babies and people with helmets on. Gender was only identified from the images, without using cues from text or image captions, as these were redundant in determining gender. Gender coding decisions were based on characteristics such as clothing, hairstyle, and presence or absence of facial hair, and age was determined by size, clothing, and facial structure (Fitzatrick \& McPherson 2010; Jackson \& Gee 2005). Once the coding scheme had been developed it was tested for inter-rater reliability by two technicians (one male and one female), and kappa was calculated to be 0.94 , which is usually interpreted as high reliability between coders (Seale \& Tonkis 2012). In order to explore gender representation by target age of book, bibliographic data was used to categorize the books in the sample into those aimed at Key Stage One and under (children aged up to seven years old), and those aimed at Key Stage Two upwards (children aged from seven years upwards) (See Table 2).

Table 2: Total number of books in sample by subject and target age

\begin{tabular}{|l|l|l|l|}
\hline & $\begin{array}{l}\text { Key Stage 1 and under } \\
(\text { age }<7)\end{array}$ & $\begin{array}{l}\text { Key Stage 2 and } \\
\text { upwards (age 7+) }\end{array}$ & Total \\
\hline Biology & 53 & 24 & 77 \\
\hline Physics & 16 & 37 & 53 \\
\hline Maths & 21 & 9 & 30 \\
\hline Total & 90 & 70 & 160 \\
\hline
\end{tabular}

Qualitative procedure: Visual analysis 
For the qualitative study, the eighteen books featuring astronauts and eight books about doctors were read closely and analysed using a survey instrument, developed from the literature to assess 'theoretically derived aspects of sexism' (Diekman \& Murnen 200: 377) (See Figure 1). The survey instrument was used to examine images, captions and the text of the books (Barbercheck 2001; Osei-Kfi \& Torres 2015). From the use of the survey instrument, recurring patterns in gendered distributions of clothing and activities emerged, and additional readings were then carried out to examine each of these aspects in detail (Zacharias 2004).

\section{General}

- Are females positioned prominently or in the background? (Diekman \& Murnen 2004)

- Are females younger? (Fitzpatrick \& McPherson 2009; Diekman \& Murnen 2004)

- Do captions or text use sexist language eg men for people? (Diekman \& Murnen 2004: 384)

\section{Job roles and status}

- Are males pictured in lower status jobs than females? (Diekman \& Murnen 2004)

- Are men and women performing same job equally? (Diekman \& Murnen 2004)

- If the book is mainly about an occupation, is there an overall sense that males and females are just as likely to do it? (Diekman \& Murnen 2004)

- If the occupation is traditionally gendered (eg nurse) are their instances where the other gender is portrayed? (Diekman \& Murnen 2004)

\section{Activity, location and tools}

- What are the doctors or astronauts doing in the pictures? (Jackson 2007)

- Are females as likely to be doing a particular activity?

- What is the activity level - static / busy / active? (Fitzpatrick \& McPherson 2009: 131)

- Are females doing less exciting or dangerous tasks (eg administration, rather than surgery or piloting a space shuttle)?

- Is one person serving or caring for another? (Jackson \& Gee 2005)

- Where are the professionals located? (Jackson 2007) Are they in places reserved for that occupation (eg space station, operation theatre) or in places open to the general public (eg waiting rooms)?

- What are the doctors or astronauts holding, or immediately next to? (Jackson 2007; Poarch \& Turner 2001)

- Are females associated with smaller objects? (Diekman \& Murnen 2004)

\section{Clothing}

- Are females as likely to be wearing the stereotypic 'uniform' of the job (eg white coat, space suit) (Long et al. 2001)

- Do women have long hair? (Jackson \& Gee 2005)

- Do women wear trousers? (Jackson \& Gee 2005)

- Are males dressed more formally?

Figure 1: Survey instrument for qualitative analysis of visual data 


\section{Findings and Analysis}

\section{Content analysis}

Results reveal that overall males were three times more likely to be pictured than females in the books reviewed (see Table 3). However, important differences between subjects emerged for the gender balance of images of adults. Books about biology had an almost even gender representation, with males being depicted $53.4 \%$ of the time, but males were more likely to be pictured in books relating to physics (87.1\%) and maths (77.6\%). Depiction of children in books is more gender balanced than for images of adults; images of boys made up $53.6 \%$ of those shown in biology, $66.2 \%$ of those shown in physics, and $54.6 \%$ of those shown in maths. In addition, books aimed at younger children were more gender balanced than those aimed at older children: for key stage one $49.5 \%$ of images of adults were male but for key stage two the gender imbalance was more marked with $78.3 \%$ of images of adults being male.

In order to test whether the frequencies of images for males and females could have occurred by chance, we carried out a series of goodness of fit $\chi^{2}$ tests. The tests demonstrated that, overall there were significantly more males depicted in the children's science books than would be expected by chance $\left(\chi^{2}=318.91, d f=1, p<.001\right)$. This supported the prediction in our first hypothsis. We then tested whether there were significant differences in the number of males and females in children's books in different subjects (maths, physics, and biology). The second hypothesis predicted that books about gender balanced STEMM fields would show no difference between the number of men and women pictured in the books, and this is indeed what we found for the books about human biology and medicine $\left(\chi^{2}=9.22, d f=1, p=.002\right)$. In contrast, in physics and maths books, adult women were depicted significantly fewer times than men than would be expected by chance, as predicted by our third hypothesis (see Table 3). When we repeated these analyses for images of children, we found no significant differences in the number of images of boys and girls in the biology, physics or maths books, which confirmed our fourth hypothesis (see Table 3).

Finally, we tested our final hypothesis, which predicted that books aimed at younger children would have a more balanced representation of gender than those aimed at older children. We found that this was indeed the case: the frequency of depiction for adult women in books was significantly lower than men in books for older children, but not for those aimed at children under 7 . When we tested the frequency of images of girls in the books, we found a similar pattern. The proportion of girls was significantly lower than would be expected by chance in books for older children, but not for books aimed at younger children (see Table 3).

Table 3: $\chi^{2}$ values for images of males and females in books, by subject, publication decade and target age.

\begin{tabular}{|l|l|l|l|}
\hline & $\begin{array}{l}\text { Total number of } \\
\text { Males }\end{array}$ & $\begin{array}{l}\text { Total number of } \\
\text { Females }\end{array}$ & $\chi^{2}(\mathrm{df}=1)$ \\
\hline All images & $\begin{array}{l}3773 \\
(74.8 \%)\end{array}$ & $\begin{array}{l}1273 \\
(25.2 \%)\end{array}$ & $1238.61^{*}$ \\
\hline
\end{tabular}




\begin{tabular}{|c|c|c|c|}
\hline Images of Ac & & & \\
\hline Biology & $\begin{array}{l}1086 \\
(53.4 \%)\end{array}$ & $\begin{array}{l}949 \\
(46.6 \%)\end{array}$ & 9.22 \\
\hline Physics & $\begin{array}{l}748 \\
(87.1 \%)\end{array}$ & $\begin{array}{l}111 \\
(12.9 \%)\end{array}$ & $472.37^{*}$ \\
\hline Maths & $\begin{array}{l}574 \\
\text { (77.6\%) }\end{array}$ & $\begin{array}{l}166 \\
(22.4 \%) \\
\end{array}$ & $224.95^{*}$ \\
\hline \multicolumn{4}{|c|}{ Images of Children } \\
\hline Biology & $\begin{array}{l}848 \\
(53.6 \%) \\
\end{array}$ & $\begin{array}{l}733 \\
(46.4 \%) \\
\end{array}$ & 8.37 \\
\hline Physics & $\begin{array}{l}51 \\
\text { (66.2\%) } \\
\end{array}$ & $\begin{array}{l}26 \\
\text { (33.8\%) } \\
\end{array}$ & 8.12 \\
\hline Maths & $\begin{array}{l}466 \\
(54.6 \%)\end{array}$ & $\begin{array}{l}388 \\
(45.4 \%)\end{array}$ & 7.12 \\
\hline \multicolumn{4}{|c|}{ Images of Adults } \\
\hline Books KS1 & $\begin{array}{l}753 \\
(49.5 \%) \\
\end{array}$ & $\begin{array}{l}767 \\
(50.5 \%) \\
\end{array}$ & .13 \\
\hline Books KS2+ & $\begin{array}{l}1655 \\
(78.3 \%) \\
\end{array}$ & $\begin{array}{l}459 \\
(21.7 \%) \\
\end{array}$ & $676.64 *$ \\
\hline \multicolumn{4}{|c|}{ Images of Children } \\
\hline Books KS1 & $\begin{array}{l}1045 \\
(53.6 \%) \\
\end{array}$ & $\begin{array}{l}906 \\
(46.4 \%) \\
\end{array}$ & 9.903 \\
\hline Books KS2+ & $\begin{array}{l}320 \\
(57.0 \%)\end{array}$ & $\begin{array}{l}241 \\
(43.0 \%) \\
\end{array}$ & $11.13^{*}$ \\
\hline
\end{tabular}

The results of the content analysis confirm predictions that females are under-represented in children's science trade books. However, our findings indicate that there are differences in the representation of gender between different STEMM fields, with biology/medicine having a more equitable distribution than maths and physics. Inferential statistics show that while these gender differences for maths and physics are statistically significant in images of adults, images of children demonstrate no significant difference in gender representation. The results of the current study also show that children's science books display increasingly gender stereotypical images as the target age of the books increases. These results echo the findings of a number of studies of children's literature, which report children to be portrayed more equitably than adults (Gooden \& Gooden 2001; Hamilton et al. 2006; McCabe et al. 2011), and younger children to receive a more balanced representation of gender than older children (Evans \& Davies 2000).

\section{$\underline{\text { Visual analysis }}$}


In the discussion that follows, key images that encapsulate the dominant themes in the discourse are described and discussed to illustrate our findings.

\section{Suspended in space}

'Living in space' is a two-page spread in a book about space that focuses on the work that astronauts carry out whilst living on the international space station. As you turn the page, your eyes are drawn to the central image of a female astronaut in a dark blue t-shirt, resting her head on her hand, looking dreamily out of the windows of the space station at the earth below. The text on the page explains that the work of an astronaut is doing experiments, keeping fit and doing maintenance on the space station. Around the edge of the page are smaller images: One shows a male dressed in sportswear, straining to lift the weights of the 'Resistive Exercise Device', another smaller image shows a male astronaut staring intently at his green rubber gloved hands inside a 'glove box', a small transparent laboratory, which contains wires and other devices that the astronaut is manipulating (Stott 2012: 66). The juxtaposition of the images and text on the page communicates that although women do go into space, they do not appear to do the work of an astronaut whilst they are there.

In all the books about space studied, there were no pictures of female astronauts piloting shuttles, doing experiments, using computers, or exercising. The most commonly pictured activity of female astronauts was of floating in zero gravity, and the most commonly used piece of equipment for a female astronaut was a camera. This pattern of females being depicted as less active than males is one found in a variety of different media. Fitzpatrick and McPherson's (2010) study of colouring books found that males were more likely to be shown in active states using gross motor movements, whereas females were more likely to be in static positions. Turner-Bowker (1996) found that male characters in children's literature were described as more potent and active than females. Furthermore, Jackson's (2007: 69) study of children decoding images in picture books showed that children decide a person's role and whether they have the skills and knowledge to do a job by what they are pictured holding and doing. It could be argued that the fact that female astronauts are not shown doing the work of an astronaut could also be interpreted as them not being able to do these tasks.

Another book pictures a female astronaut floating in a space station, with her arms holding her legs tucked up and close to her chest. She is smiling and is dressed in casual clothes and jewellery as her long blond hair billows above her head, suspended in zero gravity. The caption of the picture reads 'In zero G every day is a bad hair day' (Rickard 2010: 28). Osei-Kofi \& Torres' (2015: 535) analysis of college viewbooks found that attractive, often blond haired, females are featured as science students in laboratories 'but there is little in the images that point to their active involvement in scientific work'. This echoes the imagery in the space books as although female astronauts are present, the images do not show them actually doing science in space. In order to focus on the meaningful contribution of women, it is not enough to have images of women present in scientific environments: They must be seen to be actively doing science, otherwise they may not be interpreted as bona fide scientists (Jackson 2007). In contrast to the space books, in the medical books both male and female doctors were pictured doing the same tasks, such as examining patients, using stethoscopes, looking at x-rays, talking on the telephone and going on home visits, and there were no tasks done exclusively by one gender. 


\section{The 'assistant' stereotype}

Status can be displayed visually in a variety of ways, including through images of one person caring for, or serving, another (Jackson and Gee 2005). Two of the space books contained the same image of a female astronaut, dressed in a red t-shirt and blue trousers, using clippers to cut a male astronaut's hair (Stott 2012; Thomas 2013). A survey of online images of astronauts cutting hair reveals that there are many images available of male astronauts cutting each others' hair, and even their own. However, the use of an image of a female astronaut cutting a male astronaut's hair conjures a commonly held stereotype of women being supporting roles to the men, acting as caring assistants rather than equals. A number of studies of the representation of female scientists in various media have found women scientists portrayed as the stereotype of the 'assistant' or 'sidekick' (Flicker 2003; Osei-Kofi \& Torres 2015; Steinker \& Long 1996 cited in Long et al 2010). Furthermore, the children in Jackson's (2007:69) study interpreted the female garage worker as 'the garage "servant" as she was pictured answering the phone and carrying things, rather than fixing cars.

In the books about doctors, this association between females and being an assistant seems to have posed a challenge to some book producers. Two of the eight medical books had images of female doctors discussing a case with male nurses (Chancellor 2006; Leake 2008). The highlighting of male nurses within medical books could be considered progressive by providing imagery of men in a caring role within which they are underrepresented. However, given the stereotypes that society holds and as we have already seen, there is complexity involved in visually portraying minority STEMM professionals. As Diekman \& Murnen (2004) point out, hierarchy can be conveyed visually by proximity to significant items, maturity of the individual, or by differences in physical size, and so these things must be considered when using images to challenge gender stereotypes.

A tall uniformed male nurse holds open a patient's file, whilst a young female doctor dressed in black casual clothes with a stethoscope around her neck, looks over his shoulder at the notes. The composition of this image, with the male nurse being taller and holding the notes gives us the impression that the male is in control and therefore more senior, even though we are told on the previous page that nurses care for their patients by 'following the doctors' instructions' (Chancellor 2006: 16). In another book, a doctor and nurse are looking at an x-ray photograph held against a light box (Leake 2008). The younger, male nurse stands right beside the light box and the mature female doctor wearing a white coat stands slightly further away but is holding the x-ray photograph up to the light box. Here, the doctor's white coat, her age and the fact that she is holding the $x$-ray all give the impression that she is in charge. The producers of this book have also added an arrow with the label 'nurse' to the image of the man; perhaps they felt that without the label readers might mistake him for a doctor. Whilst this may seem a clunky way to address gender representation in medical staff, it does show that the book's producers have at least considered the gender stereotypes prevalent in medicine (Barbarcheck 2001). It is interesting to note that in both these images, readers had to use cues from text to correctly ascertain the role of the male as the images alone were ambiguous.

Who is inside that spacesuit? 
In the corner of a double page spread about spacewalks, an astronaut is pictured working on the outside of the international space station. The astronaut is wearing the iconic white padded spacesuit and is holding a large silver power drill. We can just see the edge of the astronaut's face through the reflective visor of their helmet, but it is impossible to tell their gender. The text next to the image explains the features of the power drill. In the middle of the page is a large image of another astronaut in a spacesuit floating in space, only joined to the space station by a thin cord. Next to this astronaut is his name as well as a small thumbnail image of the male astronaut putting on his space suit. Text at the top of the page reads: 'Without a spacesuit an astronaut's blood would boil and his body would blow apart' (Stott 2012: 61). The male pronouns, names and faces lead us to assume that the astronaut in the corner with the drill, whose face we cannot see, must also be male.

A survey of online images of female spacewalks revealed that the astronaut pictured with the drill is Sunita Williams, one of 11 women to have performed a spacewalk (NASA 2015). Not only was Williams not acknowledged in the montage described above, but in all the books studied there is not a single clearly identifiable image of a woman wearing an astronaut's white padded spacesuit. We suggest that it possible that younger children would not even recognize the women dressed in casual clothes inside the space station as astronauts (Jackson 2007), although further work is needed to better understand how children interpret such images. Taken together, the lack of images of women in spacesuits and spacewalking, and the excessive use of male pronouns in the text of the books studied, amounts to a symbolic annihilation of women in space (McCabe at al. 2011).

Many of the themes identified in the images of astronauts show that the concept of a female astronaut poses a challenge to the masculine ideals associated with space exploration. As Harding (1986: 59) describes, a woman scientist is in some ways a 'contradiction in terms' as the symbolic meanings of femininity are in opposition to the 'macho, virile, active and energetic' nature of science (LaFollette, 1988: 270). Jackson and Gee (2005: 125-126) assert that when depicting women in these contradictory situations, there is an apparent necessity to ensure there is also a 'traditional 'feminine' activity or marker', such as being a static bystander or being in a contained, submissive posture, in order to maintain 'constructions of active masculinity and passive femininity'. This could go some way suggesting an explanation for why our analysis shows that it is acceptable for women to be seen to be astronauts, as long as they are only shown floating about inside the space station or caring for the men, and the dangerous, daring and technical work is depicted as the still being the preserve of male astronauts.

\section{Conclusion}

As Barbercheck (2001: 120) points out, 'a prevailing assumption is that gender is irrelevant in doing science, and therefore is irrelevant in the culture of science'. However, our results show that children's science books, at least, are not gender neutral. This study has shown that women are underrepresented in children's science books and that books about biology and medicine show a more equitable representation of gender than books about physics and maths. In addition, subtle aspects of 
sexism were more likely to be found in books featuring astronauts than books about doctors. This study is unique as it analyses the depiction of gender in books about different STEMM disciplines, as well as investigating an understudied medium, that of children's science books.

The producers of children's science books have clearly made an effort to include images of female STEMM professionals. However, as Diekman and Murnen (2006: 376) point out the tone or attitude in which they are depicted can be 'equally important as the fact that they are presented at all'. In the medical books we studied, doctors are just as likely to be shown as men or women and there is no gendered division of tasks. However, the scarcity of images of female astronauts doing the work of astronauts, or wearing space suits, combined with the use of male pronouns to refer to all astronauts, amounts to a symbolic annihilation of women in space. It is clear that both the STEMM community, educators, publishers and librarians need greater awareness of the visual 'grammar' of gender and STEMM in order to provide children with a more egalitarian discourse around science and the physical sciences in particular (Osei-Kofi \& Torres 2015:527).

The books in this study were published between 1993 and 2015 and an interesting avenue of future study would be to analyse a larger sample of books to see whether there has been any change over time in the representation of gender in children's science books. As mentioned in the literature review, studies of children's literature over long time periods show that variation in the number of female main characters does exist (McCabe et al, 2011) and it would be interesting to see if this trend is mirrored in children's science books. In addition, this data for this study was collected by adult researchers and it would be interesting to explore the responses of children to the representations of people depicted in science books. 


\section{References}

Adams, S. (2015), 'What kids in 2015 want to be when they grow up', http://www.forbes.com/sites/susanadams/2015/12/14/what-kids-in-2015-want-to-be-when-they-growup/\#206284835d17 Accessed 21 December 2016.

Ali, S. (2012), 'Visual analysis', in C. Seale (ed.), Researching society and culture (3rd edn), London: Sage, pp. 283-301.

Baram-Tsabari, A., \& Yarden, A. (2008), 'Girls' biology, boys' physics: Evidence from free-choice science learning settings', Research in Science \& Technological Education, 26:1, pp. 75-92.

doi:10.1080/02635140701847538

Beilock, S. L., Gunderson, E. A., Ramirez, G., Levine, S. C., \& Smith, E. E. (2010), 'Female teachers' math anxiety affects girls' math achievement', Proceedings of the National Academy of Sciences of the United States of America, 107:5, pp. 1860-1863. doi:10.1073/pnas.0910967107

Chancellor, D. (2006), At the hospital, London: Franklin Watts.

Cheryan, S., Ziegler, S.A., Montoya, A.K., \& Jiang, L. (2016), 'Why are some STEM fields more gender balanced than others?', Psychological Bulletin, Oct 10, 2016. http://dx.doi.org/10.1037/bul0000052

Cvencek, D., Meltzoff, A. N., \& Greenwald, A. G. (2011), 'Math-Gender stereotypes in elementary school children', Child Development, 82:3, pp. 766-779. doi:10.1111/j.1467-8624.2010.01529.x

Diekman, A. B., \& Murnen, S. K. (2004), 'Learning to be little women and little men: The inequitable gender equality of nonsexist children's literature', Sex Roles, 50:5, pp. 373-385.

doi:SERS.0000018892.26527.ea

Emmison, M., \& Smith, P. (2000), Researching the visual: Images, objects, contexts and interactions in social and cultural inquiry, London: Sage.

Fitzpatrick, M. J., \& McPherson, B. J. (2010), 'Coloring within the lines: Gender stereotypes in contemporary coloring books', Sex Roles, 62:1, pp. 127-137. doi:10.1007/s11199-009-9703-8

Flicker, E. (2003), 'Between brains and breasts-women scientists in fiction film: On the marginalization and sexualization of scientific competence', Public Understanding of Science, 12:3, pp. 307-318.

doi:10.1177/0963662503123009

Frawley, T. J. (2008), 'Gender schema and prejudicial recall: How children misremember, fabricate, and distort gendered picture book information', Journal of Research in Childhood Education, 22:3, pp. 291303. doi:10.1080/02568540809594628

General Medical Council. (2016), 'List of registered medical practitioners - statistics'. http://www.gmcuk.org/doctors/register/search stats.asp Accessed 21 December 2016. 
Good, C., Aronson, J., \& Harder, J. A. (2008), 'Problems in the pipeline: Stereotype threat and women's achievement in high-level math courses'. Journal of Applied Developmental Psychology, 29:1, pp. 17-28. doi:10.1016/j.appdev.2007.10.004

Gooden, A. M., \& Gooden, M. A. (2001), 'Gender representation in notable children's picture books: 1995-1999', Sex Roles, 45:1, pp. 89-101. doi:1013064418674

Hamilton, M. C., Anderson, D., Broaddus, M., \& Young, K. (2006), 'Gender stereotyping and underrepresentation of female characters in 200 popular children's picture books: A twenty-first century update', Sex Roles, 55:11-12, pp. 757-765. doi:10.1007/s11199-006-9128-6

Harding, S. G. (1986), The science question in feminism, Milton Keynes: Open University Press.

Jackson, S. (2007), "She might not have the right tools... and he does': Children's sense-making of gender, work and abilities in early school readers', Gender and Education, 19:1, pp. 61-77.

doi:10.1080/09540250601087769

Jackson, S., \& Gee, S. (2005). “Look janet', 'no you look john': Constructions of gender in early school reader illustrations across 50 years', Gender and Education, 17:2, pp. 115-128.

doi:10.1080/0954025042000301410

Johnson, R., Onwuegbuzie, A., \& Turner, L. (2007), 'Toward a definition of mixed methods research', Journal of Mixed Methods Research, 1:2, pp. 112-133. doi:10.1177/1558689806298224

Kiefer, A. K., \& Sekaquaptewa, D. (2007), Implicit stereotypes and women's math performance: How implicit gender-math stereotypes influence women's susceptibility to stereotype threat. Journal of Experimental Social Psychology, 43:5, pp. 825-832. doi:10.1016/j.jesp.2006.08.004

LaFollette, M. (1988), 'Eyes on the stars: Images of women scientists in popular magazines', Science Technology and Human Values, 13:3/4, pp. 262-275.

Leake, D. (2008), People in the Community: Doctors, Oxford: Heinmann.

Long, M., Boiarsky, G., \& Thayer, G. (2001), 'Gender and racial counter-stereotypes in science education television: A content analysis', Public Understanding of Science, 10:3, pp. 255-269. doi:10.1088/0963$6625 / 10 / 3 / 301$

Long, M., Steinke, J., Applegate, B., Knight Lapinski, M., Johnson, M. J., \& Ghosh, S. (2010), 'Portrayals of male and female scientists in television programs popular among middle school-age children'. Science Communication, 32:3, pp. 356-382. doi:10.1177/1075547009357779

Makarova, E., \& Herzog, W. (2015), 'Trapped in the gender stereotype? the image of science among secondary school students and teachers'. Equality, Diversity and Inclusion: An International Journal, 34:2, pp. 106-123. doi:10.1108/EDI-11-2013-0097 
McArthur, L. (1998), 'Report: The portrayal of women in science books for junior readers', Science Communication, 20:2, pp. 247-261. doi:10.1177/1075547098020002005

McCabe, J., Fairchild, E., Grauerholz, L., Pescosolido, B. A., \& Tope, D. (2011), 'Gender in twentiethcentury children's books: Patterns of disparity in titles and central characters', Gender and Society, 25:2, pp. 197-226. doi:10.1177/0891243211398358

National Aeronautics and Space Administration (NASA) (2015) 'Women in Space'. http://history.nasa.gov/women.html Accessed 21 December 2016.

Nosek, B. A., Smyth, F. L., Hansen, J. J., Devos, T., Lindner, N. M., Ranganath, K. A., Tucker Smith, C., Olson, K.R., Chugh, D., Greenwald, A.G. \& Banaji, M. R. (2007), 'Pervasiveness and correlates of implicit attitudes and stereotypes', European Review of Social Psychology, 18:1, pp. 36-88. doi:10.1080/10463280701489053

Nosek, B. A., Smyth, F. L., Sriram, N., Lindner, N. M., Devos, T., Ayala, A., Bar-Anan, Y., Bergh, R., Caj, H., Gonsalkorale, K., Kesebir, S., Maliszewski, N., Neto, F., Olli, E., Park, J., Schnabel, K., Shiomura, K., Tudor Tulbure, B., Wiers, R.W., Somogyi, M., Akrami, N., Ekehammar, B., Vianello, M., Banaji, M.R. \& Greenwald, A.G. (2009), 'National differences in gender-science stereotypes predict national sex differences in science and math achievement', Proceedings of the National Academy of Sciences of the United States of America, 106:26, pp. 10593-10597. doi:10.1073/pnas.0809921106

O'Brien, L. T., Blodorn, A., Adams, G., Garcia, D. M., \& Hammer, E. (2015), 'Ethnic variation in genderSTEMM stereotypes and STEMM participation: An intersectional approach', Cultural Diversity \& Ethnic Minority Psychology, 21:2, pp. 169-180. doi:10.1037/a0037944

O'Keeffe, M. (2013), 'Lieutenant Uhura and the drench hypothesis: Diversity and the representation of STEMM careers', International Journal of Gender, Science and Technology, 5:1, pp. 4-24.

Osei-Kofi, N., \& Torres, L. E. (2015), 'College admissions viewbooks and the grammar of gender, race, and STEMM', Cultural Studies of Science Education, 10:2, pp. 527-544. doi:10.1007/s11422-014-9656-2

Poarch, R., \& Monk-Turner, E. (2001), 'Gender roles in children's literature: A review of non-awardwinning 'easy-to-read' books', Journal of Research in Childhood Education, 16:1, pp. 70-76. doi:10.1080/02568540109594975

Rawson, C. H., \& McCool, M. A. (2014), 'Just like all the other humans? Analyzing images of scientists in children's trade books'. School Science and Mathematics, 114:1, pp. 10-18. doi:10.1111/ssm.12046

Rickard, S. (2010), 123 Go! Astronaut, Watlington: Ransom.

Rose, G. (2012), Visual methodologies: An introduction to researching with visual materials (3rd edn), London: SAGE.

Seale, C. \& Tonkis, F. (2012), 'Content and comparative keyword analysis', in Seale, C. (ed.) Researching society and culture (3rd edn), London: Sage, pp. 459-478. 
Shachar, O. (2000), 'Spotlighting women scientists in the press: Tokenism in science journalism', Public Understanding of Science, 9:4, pp. 347-358.

Steffens, M. C., Jelenec, P., \& Noack, P. (2010), 'On the leaky math pipeline: Comparing implicit mathgender stereotypes and math withdrawal in female and male children and adolescents', Journal of Educational Psychology, 102:4, pp. 947-963. doi:10.1037/a0019920

Steinke, J. (2005), 'Cultural representations of gender and science: Portrayals of female scientists and engineers in popular films', Science Communication, 27:1, pp. 27-63. doi:10.1177/1075547005278610

Stott, C. (2012), Space, London: Dorling Kindersley.

Thomas, I. (2013), Stars and galaxies, London: Raintree.

Women's Engineering Society. (2016), 'Statistics on women in engineering' http://www.wes.org.uk/statistics Accessed 21 December 2016.

Yang, Y., \& Barth, J. M. (2015), 'Gender differences in STEMM undergraduates' vocational interests: People-thing orientation and goal affordances', Journal of Vocational Behavior, 91, pp. 65-75. doi:10.1016/j.jvb.2015.09.007

Zacharias, T. (2004), 'Representing otherness: collecting and analysing visual data', in Seale, C. (ed.) Researching society and culture (2nd edn), London: Sage, pp. 443-451.

Elizabeth F. Caldwell is an Academic Skills Tutor in the School of Art, Design and Architecture at the University of Huddersfield. She holds a Ph.D. in Genetics from University College London and her current research projects focus on social and cultural studies of science.

Susan Wilbraham is Senior Lecturer in Applied Psychology at the University of Cumbria. Her research interests include topics in social psychology and health such as stress, smoking and e-cigarettes, eating behaviour, weight cutting in combat sports, pregnancy and childbirth, and feminist discourse of fitness and beauty. 
